\title{
THE IMPLEMENTATION PROSPECTS OF AMBLYSEIUS SP. AS BIOLOGICAL CONTROL AGENT
}

\author{
Handoko, Latifah Evy \\ Assesment Institute for Agricultural Technology, East Java, Indonesia \\ *E-mail: epilatip08@gmail.com
}

\begin{abstract}
Amblyseius sp. was found as a natural enemy of spider mites. Amblyseius can adjust to live together with other mite predators in the development of spider mites. When conditions are favorable for the proper flow between source plants and protected plants, weeds and hedges can be of "natural ecological protection and potential sources" for phytoseiid species populations. Host species greatly affect predator performance. Predator activity increases significantly at higher temperatures. The level of predation is also affected by irradiation. There are two phytoseiid mites that have the ability to prey on $A$. fockeui even though the ability of $A$. sojaensis is somewhat lower than that of A. barkeri (Hughes). A. californicus together with a complex of indigenous predacious mites, kept Polyphagotarsonemus latus (Banks) density below economic damaging levels on time fruits.
\end{abstract}

\section{KEY WORDS}

Amblyseius, predators, natural enemy, spider mites.

Interactions among abiotic and biotic factors, such as host plant, prey, and predator, always occur in the ecosystem. Host plants and litters around them not only provide shelter and serve as food source for phytophagous/prey, but at the same time also provide shelter for predators. The microclimate of the plants, specifically temperature and humidity, exposes the organism to effects which are both favorable or unfavorable. Temperature is probably the most crucial environmental factor influencing reproduction process (Ponsoby and Copland, 1998; Engelmann, 1999; Rott and Ponsonby, 2000; Uygun and Atlihan, 2000; Wang et al., 2000). Moreover, habitat manipulation becomes necessary for crop management strategies in the future (Corpuz-Raros, 2002). Rice straws as mulch bring the advantage of increased nutrition for plant, while phytoseiid mite is beneficial for plant because it can eliminate other mite population (Aquino and Mabesa, 2002). The Phytoseiidae family consists of more than 2,400 species worldwide (Demite et al., 2018), which are used in three biological control strategies. The classical biological control aims at controlling invasive pests by introducing natural predators in the targeted area, that is the pest origin zone. In a favorable condition, the population of phytophagous insects would increase when their natural predators are absent. For example, on cassava, apple, tomato, citrus, and papaya, spider mite (Tetranychus, sp) poses as pest that attacks the plant, causing the decrease of productivity (Chazeau, 1985; Khashoven, 1981). Tetranychus, sp (Acari: Tetranychidae) has a natural predator, a family of mite called Phytoseiidae. Amblyseius, sp (Gamasida: Phytoseiidae). This species of mite is found to be a potential natural predator of spider mites (CorpuzRaros, 2002). The use of predatory mites from the family of Phytoseiidae (Acari: Mesostigmata) is a reliable strategy to minimize the use of pesticides, which can result in reducing environmental pollution, and to protect beneficial insect and mite species (Patel and Zhang, 2017). The predatory mite Amblyseius swirskii Athias-Henriot (Acari: Phytoseiidae) is one of the biological control agents among some of the most efficient pest control insect families, such as Eriophyidae, Tenuipalpidae, and Tetranychidae, which are the natural predators for insect pests such as thrips and whiteflies (Calvo et al., 2015).

Massaro et al. (2019) suggest that Amblyseius tamatavensis Blommers is a phytoseiid mite that appears to be compatible with type III-b (generalist predators that live on bare leaves). Furthermore, Cavalcante et al. (2017) report that this species is a promising natural predator for $B$. tabaci. In a previous study, the experimental release of this predator in plants 
kept on greenhouse caused a decrease in the population of $B$. tabaci in pepper plants by up to $60-80 \%$. It can be concluded that this treatment results in an increase of productivity when planting is done under laboratory conditions (Massaro et al., 2018). When this predator is fed with astigmatina mites, this treatment can facilitate eventual mass production of augmentative biological control. Amblyseius tamatavensis Blommers is reported to be found in more than 20 countries around the world (Africa, Asia, America and Oceania). Given this wide world distribution, the origin of this species is difficult to assess. However, current studies show that this species seems to not have been introduced on purpose to Brazil, where it is reported that the species does not exist in the 12 states, from the north to the southeast of the country (Demite et al., 2018). The hypothesis tested here is whether there are populations other than those studied by Cavalcante et al. (2017) that can do better to control B. tabaci.

The searching capacity and activity are highly constant in the wide habitat distribution. The potential of predators is determined by considering factors, such as population density, capability to preying per time unit (V rie, 1985), searching capacity, host specific, reproductive rate, and extensive adaptation capability (De Bach, 1964).

In cassava and apple plants, as reported by Kalshoven (1981), Amblyseius can adaptively live together with other predators of mite to suppress spider mites population. Other plants that serve as potential Amblyseius, $s p$ habitat as reported by Cotpuz-Raros (2002) are shown in Table 1.

\section{PREDATOR LIFE HISTORY}

General Identification of Amblyseius sp. Below are the descriptions of the characteristics of Amblyseius Berlese (Acarina: Phytoseiidae).

Female. It has full, smooth, creased or reticulated dorsal shield, with 10, 15, 16,17, or 19 pairs of setae, 5,6 or 7 dorsal, 2 or 3 medial, 3 or 4 anterolateral, and 4 or 5 posterolateral. Setae is minute to long and or whip-like, smooth, serrated, knobbed, stout, or a combination of some of these characters. Sternal shield is rectangular, square or horseshoe shaped, with three pairs of sternal setae and two pairs of pores. Sternal setae IV on metasternal shields has a pore each on anterior margin. Genital shield has a pair of genital setae. Ventrianal shield is vase-shaped, pentagonal or divided, with three pairs of pre-anal setae and a pair of round or crescentic pre-anal pores. On surrounding interscutal membrane primary and secondary metapodal shield are three pairs of ventrolateral setae and a pair of smooth caudolateralsetae. It has fixed digit with pilus dentilis and teeth anterior of it or along entire inner edge. There is a movable digit with $1,2,3$ or 4 teeth, mostly recurved. Spermathecae is variable. Legs can have setaceous, blunt, apatulate or knobbed macrosetae.

Males. The spermatodactyl is foot-shaped. It has ventrianal shield with three pairs of preanal setae and a pair of round or crescentic preanal pores. It has proscutum with more than four pairsm of lateral $(\mathrm{L})$ setae and postscutum with more than three lateral setae. The dorsal setae are not very tick and only some that are slightly serrated (Schicha and CorpuzRaros, 1992). McMurtry et al. (2013) and Tixier (2018) divide the Phytoseiidae family into four main categories depending on feeding habits: (i) specialized, (ii) selective, (iii) generalist, and (iv) pollen feeder.

Life Cycle. Phytoseiidae insects have four developmental stages: the oval-shaped egg, the six legged larva, and the two eight-legged stages, i.e. the protonymph and the deutonymph. The body of the larva is supported by the last two pairs of legs, the first pair serving mainly as sensory structures. Larvae and nymphs reach the next stage via molting. The egg to adult period of phytoseiid males is not generally shorter than that of the females, as is the case with spider mites (Sabelis, 1985). Detrimental impacts of non-native species on native biota have occurred through competition, predation, herbivory, habitat alteration, as well as disease and genetic effects (hybridization) (Manchester, S.J. and J.M Bullock, 2000). Local information on the biology and ecology of phytoseiid is limited to Amblyseius, an important predator of spider mite Tetranychus kanzawai Kishida, which live on several crops, 
especially cassava (Corpuz-Raros, 2002). Currently, researchers from Entomology Department have been studying the life and the effectiveness of four Amblyseius species. The development of many phytoseiid insects, including Amblyseius, takes 6-7 days to fully grow under suitable temperature at $27^{\circ} \mathrm{C}$ and $60-90 \%$ relative humidity (Gerson et al, 1990).

Host Plants and Ecological Aspects. A. hibisci (Chant) is the commonest species of phytoseiid mite on citrus and avocado in most areas of southern California (McMurtry and Johnson, 1965), while $A$. womersleyi is a predatory mite native to Japan and inhabit chrysanthemum and kidney bean plants (Maeda et al., 1999). On apple orchards in Argentina which are grown with heavy pesticides application, species that are found are Tetranychidae and Neoseiulus (Amblyseius) californicus (McGregor) (Monetti and Fernandez, 1995). Among them, A. addoensis (Van der Merwe and Ryke) is commonly found in lowlands (1500-1700 m) and Senqu valley (1500-2000 m). Meanwhile, A. sehlabatel is common in foothills $(1700-2400 \mathrm{~m})$ and mountains $(>2400 \mathrm{~m})$. Observation shows that there is a link between altitude and flora species (El-Banhawy, 2002). In Taichung, Taiwan, Amblyseius is reported as promising predator of phytophagus mites attached in mulberry (Shih, 1984). Weeds and hedges may form "natural ecological refuges and potential sources" for phytoseiid species when conditions are favourabe for their supposed moves between those source plants and the protected crop (Papaioannou-Souliotis et. al., 2000). Another suspected source of food is pollen. Rapid increase of $A$. hibisci population which coincides with the beginning of blossoming stage and mite's egg production peak shows a close correlation between mite's population and peak of flowering stage (McMurtry and Johnson, 1965). Activities of predator significantly increase at higher temperatures. Host plant species also strongly influence the effectiveness of the predators. Predation rate is also affected by photoperiod (Perdikis et al., 1999; Root and Ponsonby, 2000).

Reproductive and Behavior. The predatory mite $A$. womersleyi responses to the infested-leaf volatiles are varied from $33 \%$ to $97 \%$ among the populations (Maeda, 2001). This difference is not due to the difference in their feeding experiences, but to the genetic difference, which include the fecundity and oviposition periods of $A$. womersleyi-Shizuoka. However, the dispersal of $A$. womersleyi-Kyoto from a T. Urticae-infested bean leaf culture occurs earlier than that of $A$.womersleyi-Shizuoka. The lower dispersal ability A. womersleyiShizuoka compared to that of $A$. womersleyi-Kyoto is attributed to the difference in ability to distinguish infested plant volatiles from the non-infested one (Maeda et al., 1999). Infested leaves placed in the light attract predatory mite $A$. womersleyi, whereas those that are placed in the dark for at least 2 hours in daytime do not attract the mites. This indicates that the presence or absence of light affects the production of herbivore-induced plant volatiles. $A$. womersleyi disperses more frequently and consumes more T.Urticae eggs during the day (in the light) than at night (in the dark), whereas their oviposition rate does not differ between day and night. Presence or absence of herbivore-induced plant volatiles in the surroundings do not affect dispersal, predation, or oviposition rate of $A$. womersleyi. These results show that $A$. womersleyi's behavior coincides with the production pattern of herbivore-induced plant volatiles (Maeda, 2000). Predator population reaches unusually high levels apparently as a result of large quantities of pollen drifting from adjacent plants of Ricinus communis $L$. and is induced artificially by dusting caged branches with pollen at weekly intervals. Predatory mites confined on excised avocado leaves feed and reproduce on avocado pollen applied at an average density of only 6.6 pollen grains per square inch of leaf surface (McMurtry and Johnson, 1965). Functional response of $A$. longispinosus to TTSM increases prey density up to 40 per predator. However, the predators reach satiation point at a lower density of five to ten adult prey per female. It means that these predators are more compatible with numerical response approach (Ibrahim and Rahman, 1997; Kondo and Hiramatsu, 1999). Ambliseius cydnodactylon (Phytoseiidae) response to the increase of $T$. Urticae prey density (Tetranychidae) in absence or presence of Nymphs of bemesia tabaci (Homoptera) in Egypt shows that the consumption rate increases as prey density increases up to 32 nymphs/female/day and decreases significantly at 64 and 128 nymphs/female/day. The addition of a fixed number of $2^{\text {nd }}$ instar nymphs of $B$. tabaci (10 individuals) to each TSSM prey density is tested to significantly reduce consumption of spider mites, while the 
female predators respond in similar faction to increased prey density. Reproduction increases as prey density increases and reaches maximum at 32 nymphs/female/day. The addition of $B$. tabaci nymph substantially increases the reproduction at every density (EIBanhawy et al., 2001). Intraguild predation and cannibalism are common among predaceous phytoseiid mites (Acari phytoseiidae). Nevertheless, the nutritional benefits gained by these processes are poorly understood. All generalist and specialist Phytoseiid mites are able to complete juvenile development with both con- and heterospecific preys. Juvenile development of generalist species is shorter with heterospesific prey than with conspecific prey, whereas the development of specialist $P$. macropilis does not differ between prey types. All generalist species are able to sustain oviposition by intraguild predation. No specialist sustains oviposition by intraguild predation or cannibalism. Overall, generalist species gains equal or more nutritional benefits from intraguild predation than from cannibalism and is able to utilize phytoseiid intraguild prey as an alternative food source. Specialist species gains equal or more nutritional benefits from cannibalism than from intraguild predation. For specialist species, con- and heterospecific phytoseiids may be considered supplemental food only (Schausberger and Croft, 2000).

\section{EVIDENT OF EFECTIVE PREDATOR}

In apple orchards, researchers manipulate the size and number of predator refuges to conserve predator population. A. andersoni is the dominant species in lowland orchards, while another phitoseiid, Euseius finlandicus, are commonly found in highland orchards (Markoyiannaki-Printzioui et al., 2000). The population density of $A$. ovalis was the highest among the five predaceous mites, but its distribution pattern does not match that of its prey, $T$. kanzawai on mulberry plant. Predation by $A$. ovalis does not show a promising effect in suppressing spider mite population. On the other hand, $A$. womensleyi matches spider mite population distribution. Low seasonal population densities and unmatched population distributional pattern of $A$. dekleoni, $A$. okinawanus, and $A$. maai with the spider mite population have been studied, and the results show that these predators are not satisfactory biological control agents for spider mite compared to the five tested predators (Shih, 1984). The number of nymphs and adults of peach silver mite, Aculus fockeui, consumed by the females of two types of phytoseiid mites, $A$. sojaensis and $A$. eharai, are 9.2 and 13.3 respectively, when feeding is observed for $10 \mathrm{~min}$. Functional responses of the phytoseiid mite to the density of $A$. fockeui shows saturation curves, in which the maximum number of A. fockeui consumed per female per day is 300 and 400 for $A$. sojaensis and $A$. eharai, respectively. Thus, the two phytoseiid mites have great ability to prey on $A$. fockeui although the predation ability of $A$. sojaensis is somewhat inferior to that of $A$. barkeri (Hughes), which seems erratic. A. californicus together with a complex of indigenous predacious mites can keep Polyphagotarsonemus latus (Banks) population below the economic damaging level during fruiting stage (Pena and Osborne, 1996).

Combination of spraying permetrin and releasing predatory mite $A$. womersleyi Schicha is proven to be successful in suppressing the population of tea pest $T$. kanzawai. Although the mortality rate of the tested adult females in response to SP increases from 6.5 to $89.3 \%$, and the mortality is above $95 \%$ when several carbamate and organophospate insecticides are applied, the effectiveness of $A$. womersleyi as a biological control agent is successfully demonstrated in the present study (Mochizuki, 2003). Naturally beneficial mites such as phytoseiid mite $A$. californicus (McGregor) and insects like Stethorus punctilum (Weise), Conwentzia psociformis (Curtis) and others, are proven to be able to control the population of $T$. urticae (Koch) with efficiency rate similar to that of chemical control. In most crops, $A$. californicus is the main predator, acting either alone or together with other beneficial organism. These results are in line with the findings of a study in strawberry crops in the regions in Valencia by Maoz et al. (2011) who find that naturally occurring predation is able to control the population of spider mites and maintain the population below the damaging level.

Research in the UK indicates that $A$. californicus can be an efficient predator of spider mites under high temperature and low humidity conditions. Laboratory studies show that 
temperature at $30^{\circ} \mathrm{C}$ has no effect on the predatory activity or behavior, while predatory activity (shown by the number of spider mites eaten) is the highest on low humidity $(30 \%)$. Considering the host plant factor, pepper is the best host, followed by tomato and cucumber. Eggplant is the least favourable host, as it often serves as biocontrol agents. A. californicus and its relative, $A$. fallacis are reported to be slower feeders, but they are more tolerant to residues of some pesticides and are able to endure the absence of spider mites by feeding on other mites and pollen (Ferguson, 2003).

Researchers have introduced a mass-reared pyrethroid-resistant strain of the predatory phytoseiid mite $A$. fallacis (Garman) into a peach orchard in Ontario in an attempt to control the population of phytophagous mites Panonychus ulmi Koch and T. urticae Koch (Acari: Tetranychidae). In a study, 1,000 and 2,000 mites per tree were released at three different times. The releases of 2,000 mites per tree in June and July resulted in significantly higher phytoseiid population density than that of the control trees. However, the population density of P.ulmi or T. urticae was not significantly affected by any release rate or by timing. The release of 1,000 A. fallacis per tree, or of any density in August, did not significantly increase phytoseiid population. In the following year, population dynamics of both phytoseiid and phytophagous mites were not significantly affected by the previous year's release. It can be concluded that $A$. fallacis can be an effective predator in some fruit orchards. However, further research is necessary to find the best timing, release rate, and spraying modification, as well as to find the best crops that work well with this predator. Thus, it can be used to justify the role of this species for biological control in Ontario peach orchards (Lester, 1999).

The compatibility of Orius laevigatus Fieber with A. cucumeris Oudemans as predators of Frankliniella occidentalis Pergande was assessed in 24-hour tests on French bean leaf discs. At varying densities of $A$. cucumeris and $F$. occidentalis in the presence of a single female $O$. laevigatus, it was found that $O$. laevigatus fed on both organisms to a similar extent, and thus raising questions as to the suitability of this combination of predators in the biocontrol of $F$. occidentalis. In a similar trial assessing the compatibility of $O$. Laevigatus with Iphiseius degenerans or Amblyseius degenerans Berlese, $O$. laevigatus is found to prey on $F$. occidentalis more than on $A$. degenerans. It is hypothesized that $O$. laevigatus and $A$. degenerans could be used simultaneously in the biocontrol of $F$. occidentalis with minimal interference between them (Wittmann, 1997). In a previous study, the functional response of adult females of predatory mites Euseius finlandicus, $A$. finlandicus, and $A$. andersoni to larvae and adult females of red spider mite $P$. ulmi was observed on apple and peach leaf disks in the laboratory at $25^{\circ} \mathrm{C}$ and $16: 8$ (L:D). For $P$. ulmi adult females, the predation efficiency of $E$. finlandicus was higher on peach leaf disk than on apple leaf disk, while predation efficiency of $A$. andersoni was higher on apple leaf disk than on peach leaf disk. Predation efficiency of $P$. ulmi larvae by either predator did not differ significantly in apple and peach leaf disks. On both plants, $A$. andersoni had a higher predation rate than $E$. finlandicus, as shown by the effect on predation efficiency of $A$. andersoni and $E$. finlandicus when they preyed on P. ulmi larvae (Dimitris, 2000). Phytoseiid mites from christmas tree (Picea abies and Abies nordmanniana) in England are potential biocontrol agents of Eriophyoid and Tetranichid mites (Fitzgerald and Solomon, 2000). Varying release rates and release frequencies of $A$. californicus (Acari: Phytoseiid) are necessary to significantly reduce Oligonychus perseae density. Releasing 1000 or 2000 A. californicus twice per tree results in $O$. perseae population control similar to that of petroleum oil treatments. The cumulative number of predators released per tree is more important than the number of released predators (Hoddle et al., 2000). An experiment involving mistblower which successfully dispensed viable $A$. californicus mixed with corn grits on to avocado trees resulted in the recovery of predator population on the trees by up to 16 days post-application (Takano-Lee and Hoddle, 2001).

\section{RESPONSE TO PESTICIDES APPLICATIONS}

Selective use of pesticides that are harmless against natural predators is necessary to achieve integrated pest management. The use of pesticides such as pyrethroids for 
controlling lepidopteran and dipteran pest population can severely disturb the nature balance by killing or repelling acarine predators. After spraying, phytophagous mite populations subsequently increases above economic thresholds. Number of phytoseiid mites in sprayed plantations is reported to be low, while phytoseiid mites are on high population in larger, unsprayed trees on the same sites (Fitzgerald and Solomon, 2000). Fluctuations of phytophagus and predatory mites are analyzed for comparison and it is revealed that periods with string pesticide applications show decreases of $A$. californicus population and outbreaks of $P$. ulmi population. Conversely, trees that are not sprayed show an abundance of $A$. californicus and a decrease of phytophagus population (Monetti and Fernandez, 1995). Bifenazate at the full field rate is moderately toxic to phytoseiid $(37-81 \%$ mortality) but less toxic at half and quarter rates $(0-44 \%$ and $0-11 \%$ respectively). Pymetrozine is non-toxic to all predators at all rates. Phytoseiid population in hop yards seems unaffected by single application of half of three-quarter rate of bifenazate and a full rate of pymetrozine. Bifenazate and pymetrozine show great potential as selective pesticides that can be used in a sustainable hop arthropod control program based on the principles of implementation and conservation of endemic natural predators (James, 2000). The application of a pyrethroid spray is shown to result in a major disturbance to natural predator (acarine) population dynamics in the apple orchard for up to 11 weeks after spraying. In apple orchards, the use of pesticides such as pyrethroids as lepidopteran and dipteran pest control can severely disturb the nature balance by killing or repelling acarine predators. After spraying, phytophagous mite population will often subsequently increase above economic thresholds. To conserve predator population, researchers have manipulated the size and number of predator refuges (Lester et al., 1998). A. andersoni is the dominant species in lowland orchards, while Euseius finlandicus are most common in highland orchards. The tolerance of their populations to treatments with fungicides (especially sulphur, copper compounds, pyrimidines, and triazole) and selective insecticides observed during the tree-year survey is probably due to the development of tolerant strains (Markoyiannaki-Printzioui et al., 2000). Artificial laboratory selection for resistance and susceptibility to methidathion was performed in $A$. womersleyi Schicha. After four selections for susceptibility, the resistance ratio $(\mathrm{R} / \mathrm{S})$ at the Lc50 increased from 16 to 342 . The toxicity level of eight pesticides was evaluated in the $R$ and $S$ strains of this phytoseiid mite. The highest resistance ratios were observed for methidathion, acephate, and malathion, for which the $R$ strains were respectively $311,20.4$, and 13.1 times more resistant than the S strains (Sato et al., 2000).

\section{CONCLUSION}

Amblyseius is a very important predator that is able to reduce the population of spider mites so that the damage can be suppress below the economic damage level. At the time, University Putra Malaysia and Biohelp-Vienna Austria are able to commercialize this predator. Functional response of Amblyseius to spider mite increases as prey density increases up to 40 per predator. However, the predator reaches satiation at a lower density of five to ten adult prey per female. This indicates that this predator is more compatible to be implemented with numerical response approach. Amblyseius can adaptively live together with the other predatory mites and both can work well in suppressing the spider mite population. This phenomenon possesses no significant difference in effectiveness compared with pesticide application in controlling the population of spider mites.

\section{REFERENCES}

1. Mabesa. 2002. Off-season production of Honeydrew melon (Cucumis melo L.) using mulch and row cover. The Phil. Agric. Sci. 85(3): 221-229.

2. Calvo F.J., Knapp M., Van Houten Y.M., Hoogerbrugge H., Belda J. E. 2015. Amblyseius swirskii: What made this predatory mite such a successful biocontrol agent? Exp. Appl. carol. 65: 419-433. Doi:10.1007/s10493-014-9873-0 
3. Cavalcante A.C.C., Mandro M.E.A., Paes E.R., and Moraes G. J. 2017. Amblyseius tamatavensis Blommers (Acari: Phytoseiidae) a candidate for biological controlo of Bemisia tabaci (Gennadius) biotype B (Hemiptera: Aleurodidae) in Brazil. Intern. J. Acarol., 43: 10-15. Doi: 10.1080/01647954.2016.1225816.

4. Chazeau, J. 1985. Predaceous Insects. in. Helle, W. and M.W. Sabelis (Ed). Spider mites their biology. Natural enemies and control. Vol. 1b. pp 211-246.

5. Corpuz-raros, L.A. 2002. Philippine Acarine Biological Control Agents: Status, Bioecology and Research Prospects. The Phil. Agric. Sci. 85(2): 137-154.

6. Demite, P. R., DE Moraes, G. J., MCMurtry, J. A., Denmark, H. A., and Castilho, R. C. 2018. Phytoseiidae Database. Available online at: www.lea.esalq.usp.br/phytoseiidae (Accessed June 07, 2018).

7. EL-Banhawy, E.M. 2002. Survey of Predatory Mites in the Kingdom of Lesotho (Africa): Notes on Altitudinal Preference of Predatory Mites and Description of a New Species (Acary: Phytoseiidae). Internat. J. Acarol. 28: 187-191.

8. Hafez S.M., S.A. Saber. 2001. Respon of Amblyseius cydnodactylon (Phytoseiidae) to Increasing Prey Density of Tetranychus urticae (Tetranychidae) in Absence or Presence of Nymphs of Bemesia tabacci (Homoptera) in Egypt. Internat. J. Acarol. 27: 242-244.

9. EL-Laithy, A.Y.M. 1996. Integrated Control of Two Spider Mite, Tetranychus urticae on Cucumber Growth Under Plastichouse Conditions in Egypt. Entomophaga 4(2): 485-491.

10. Engelman, F. Reproduction in Insects. In: Huffaker C.B. and A.P. Gutierrez, 1999. Ecological Entomology. Second Edition. John Wiley and Sons, Inc. Canada. 123-155.

11. Ferguson, G. 2003. Greenhouse Vegetable IPM Specialist, Ontario Ministry of Agriculture and Food, Harrow, Ontario. http:www.search.gov.on.ca:8002/compass?viewtemplate $=$ simple 1 .

12. Fitzgerald, J.D. and M.G. Solomon. 2000. Phytoseiid Mites from Christmas Tree (Picea abies and Abies nordmanniana) Plantations in England: Potential Biocontrol Agents of Eriophyoid and Tetranychidae Mites. Internat. J. Acarol. 193-196.

13. Gerson, U. And R.L. SMILEY. 1990. Acarine biological agent. Chapman and Hall. London. Pp 174.

14. Helle, W. and M.W. Sabelis. 1985. Spider Mites Their Biology, Natural Enemies and Control. Vol. IB. Elsevier Science Publishing Company Inc. New York. 485 p.

15. Hoddle, M.S., L. Obinson, and J. Virzi. 2000. Biological Control of Oligonychus Perseae (Acari: Tetranychidae) on Avocado: III. Evaluating the Efficacy of Varying Realease Ratet and Realease Frequency of Neoseiullus Californicus (Acari: Phytoseiidae). Internat. J. Acarol. 26: 203-214.

16. Ibrahim, Y.B. and R.B. Abdul rahman. 1997. Influence of Prey Density, Species and Developmentl Stages on The Predatory Behavior of Ambliseius Longispinosus (Acari: Phytoseiidae). Entomophaga 42(3): 319-327.

17. James, D.G. 2002. Selectivity of Acaricide, Bifenazate, and Aphicide, Pymetrozen, to Spider Mite Predators in Washington Hops. Internat. J. Acarol. 28:175-186.

18. Kalshoven, L.G.E. 1981. Pests of crops in Indonesia. Revised and translated by P.A. Van Der Laan. P.T. Ichtiar Baru-Van Hoeve, Jakarta.

19. Kondo, A. and T. Hiramatsu. 1999. Predatory Ability of Two Species of Phytoseiid Mites (Acari: Phytoseiidae) on The Peach Silver Mite, Aculus Forkeui (Nalepa et Troussart) (Acari: Eriohydae). Appl. Entomol. Zool. 34(4): 485-487.

20. Lester, P.J., H.M.A. Thistlewood and R. Harmsen. 1998. The Effects of Regufe Size and Number on Acarine Predator-Prey Dinamics in a Pesticide-Disturbed Apple Orchard. Journal of Apllied Ecology. 35: 323-331.

21. Markoyiannaki-Printzioui, D., P. Papaioannou-S., G. Zeginis, and C. Giatropoulus. 2000. Observvations on Acarofauna in Four Aplle Orchards of Central Greece. I. Incidence of Pedoclimatic Conditions and Agricultural Techniques on Phytoseiid Mites (Acari: Phytoseiidae). Acarogia. Tome XLI Fasc. 1-2. 109-126.

22. Maeda, T., J. Takabayashi, S. Yano, and A. Takafuji. 1999. Response of the predatory mite, Amblyseius womwesleyi (Acari: Phytoseiidae), toward herbivore-induced plant 
volatiles: Variation in response between two local populations. Appl. Entomol. Zool. 34(4): 449-454.

23. Manchester, S.J. and J.M. Bullock. 2000. The Impacts of Non-native Species on UK Biodiversity and the Effectiveness of Control. Journal of Applied Ecology. 37: 845-864.

24. Maoz, Y., Gal, S., Argov, Y., AND M. Coll. 2011. Biocontrol of perse mite, Oligonychus perseae, with an exotic spider mite predator and an indigenous pollen feeder. J. Biological Control. 59 (2): 147-157.

25. Massaro, Marcela and MOraes, G. J. De. 2019. Predation and oviposition potensial of Brazilian population of the predatory mite Amblyseius tamatavensis (Acari: Phytoseiidae) on eggs of Bemisia tabaci (Insecta: Hemiptera). Open scie in Acarology. 59(1):120-128.

26. Massaro M., Montrazi M., Melo J.W.S., and Moraes G.J. 2018. Production of Amblyseius tamatavensis with Thyreophagus crasentiseta (Acari: Phytoseiidae, Acaridae). International Journal of Pest Management (in press).

27. McMurtry, J.A. and H.G. JOHNSON. 1965. Some factors influencing the abundance of the predaceous mite Amblyseius hibisci in Southern California (Acarina: Phytoseiidae). Annals of the entomological society of America. 59(1): 49-56.

28. MCmurtry, J. A., Sourassou, N. F., and Demite, P. 2015. "The Phytoseiidae (Acari: Mesostigmata) as biological control agents," in Prospects for Biological Control of Plant Feeding Mites and Other Harmful Organisms. Progress in Biological Control, Vol. 19, eds D. Carrillo, G. de Moraes, and J. Peña (Cham: Springer), 133-149. doi: 10.1007/978-3319-15042-0_5.

29. Monetti, L.N. and N.A. Fernandez. 1995. Seasonal population dinamics of the European Red Mite (Panonychus ulmi) and its predator Neoseiulus californicus in a sprayed apple orchard in Argentina (Acari: Tetranychidae, Phytoseiidae). Acarologia. Tome XXXVI Fasc. 4: 325-331.

30. Papaioannou-Souliotis P., D. Markoyiannaki-Printziou, and G. Zeginis.2000. Observations on Acarofauna in Four Apple Orchards of Central Greece. II. Green Cover and Hedges as Potential Sources of Phytoseiid Mites (Acari: Phytoseiidae). Acarologia. Tome XLI Fasc.4. 411-427.

31. Patel K., and Zhang Z.-Q. 2017. Functional and numerical responses of Amblydromalus limonicus and Neoseiulus cucumeris to eggs and first instar nymph of tomato/potato psyllid(Bactericera cockerelli). Syst. Appl. Acarol. 22: 1476-1489. Doi: 10.11158/saa.22.9.12.

32. Pena, J.E. and L. Osborne. 1996. Biological Control of Polyphagotarsonemus Latuss (Acari: Tarsonemidae) in Greenhouses and Field Trials Using Introductions of Predacious Mites (Acarina: Phytoseiidae). Entomophaga 41(2): 279-285.

33. Ponsonby, D.J. and M.J.W. Copland. 1998. Environmental Influences on Fecundity,Egg Viability, and Egg Cannibalism in The Scale Insect Predator, Chilocorus Nigritus Biocontrol 43: 39-42.

34. Perdikis, D.CH., D.P. Lykouressis and L.P. Economou. 1999. The Influence of temperature, Photoperiod and Plant Type on The Predation Rate of Macrolophus pygmaeus on Myzus persicae. Biocontrol 44: 281-289.

35. Root, A.S. and D.J. Ponsonby. 2000. The Effects of Temperature, Relative Humidityand Host Plant on the behavior of Stethorus punctilium as a Predator of Two-Spotted Spider Mite, Tetranychus urticae. Biocontrol 45:155-164.

36. Sato, M.E., T. Miyata, A. Kawai, and O. Nakano. 2000. Selection for resistence and susceptibility to methidation and cross resistance in Amblyseius womersleyi Schicha (Acari: Phytoseiidae). Appl. Entomol. Zool. 35(3): 393-399.

37. SChausberger, P. and B.A. Croft. 2000. Nutritional Benefits of Intraguild Predation and Canibalsm Among Generalist and Specialist Phytoseiids Mites. Ecological Entomology. 25: 473-480.

38. Schicha, E. and Corpuz-raros, L.A. 1992. Phytoseiidae of The Phillippines. Indira Publishing House. Michigan, USA. 190 p. SHIH, T.CH. 1984. Field evaluation of five species of Amblyseius on Tetranychus kanzawai. In GRIFFITHS, D.A. and C.E. BOWMAN: 710-716. Acarology VI (2). Ellis Horwood Limited. New York. 
39. Takano-lee, M. and M.S. Hoodle. 2001. Biological Control of Oligonychus Perseae (Acari: Tetranychidae) on Avocado: IV. Evaluating the Eficacy of a Modified Misblower to Mechanicaly Dispense Neoseiulus californicus (Acari: Phytoseiidae). Internat. J. Acarol. 27: 157-169.

40. Tixier M-S. 2018. Predatory Mites (Acari: Phytoseiidae) in Agro-Ecosystems and Conservation Biological Control: A Review and Explorative Approach for Forecasting Plant-Predatory Mite Interactions and Mite Dispersal. Front. Ecol. Evol. 6:192. doi: 10.3389/fevo.2018.00192.

https://www.frontiersin.org/articles/10.3389/fevo.2018.00192/full diakses 21 April 2020.

41. Uygun, N. and R. Atlihan. 2000. The effect of temperature on development and fecundity of Scymnus levaillanti. Biocontrol. 45: 453-462.

42. Walzer, A. and P. Schausberger. 1999. Canibalism and Interspecific Predation in the Phytoseiid Mites Phytoseiulus persimilis and Neoseiulus californicus: Predation rates and Effect on Reproduction and Juvenile Development. Biocontrol. 43: 457-468. 